\title{
PROTECTIVE IMMUNE RESPONSE TO EXPERIMENTAL INFECTION WITH SARCOCYSTIS NEURONA IN C57BL/6 MICE
}

\author{
Author(s): Sharon G. Witonsky, Robert M. Gogal Jr. , Robert B. Duncan , and David S. Lindsay \\ Source: Journal of Parasitology, 89(5):924-931. 2003. \\ Published By: American Society of Parasitologists \\ DOI: http://dx.doi.org/10.1645/GE-67R \\ URL: http://www.bioone.org/doi/full/10.1645/GE-67R
}

BioOne (www.bioone.org) is a nonprofit, online aggregation of core research in the biological, ecological, and environmental sciences. BioOne provides a sustainable online platform for over 170 journals and books published by nonprofit societies, associations, museums, institutions, and presses.

Your use of this PDF, the BioOne Web site, and all posted and associated content indicates your acceptance of BioOne's Terms of Use, available at www.bioone.org/page/terms_of_use.

Usage of BioOne content is strictly limited to personal, educational, and non-commercial use. Commercial inquiries or rights and permissions requests should be directed to the individual publisher as copyright holder. 


\title{
PROTECTIVE IMMUNE RESPONSE TO EXPERIMENTAL INFECTION WITH SARCOCYSTIS NEURONA IN C57BL/6 MICE
}

\author{
Sharon G. Witonsky, Robert M. Gogal, Jr.*†, Robert B. Duncanł, and David S. Lindsay* \\ Department of Large Animal Clinical Sciences, Virginia-Maryland Regional College of Veterinary Medicine, Virginia Polytechnic Institute and \\ State University (Virginia Tech) Blacksburg, Virginia 24061-0442. e-mail: switonsk@vt.edu
}

\begin{abstract}
Immunocompetent C57BL/6 mice were infected with Sarcocystis neurona merozoites to assess the protective immune response to active infection. Using a direct agglutination test, all infected mice seroconverted to $S$. neurona merozoite antigens by day 14 postinfection (PI). Further, mice developed splenomegaly and bilateral symmetrical lymphadenopathy by day 14 PI, which appeared to be resolving by day 28 PI. Histologic analysis revealed a marked increase in germinal center formation in the spleen and lymph nodes by day 14 PI. Corresponding to gross and histopathological changes, the percentage of B-cells decreased significantly by day 14 PI but then increased significantly and persisted at day 28 PI in the blood, spleen, and multiple lymph nodes. There was a sharp nonspecific significant decrease in CD4 percentages by day 14 PI in the blood, spleen, and lymph nodes. Early-activation CD8 lymphocytes (CD62/CD8) were significantly down-regulated coinciding with a significant compensatory up-regulation of memory (CD44/CD8) lymphocytes in multiple organs. We propose that the protective cell-mediated immune response to $S$. neurona involves both CD4 and CD8 cells, with CD8 lymphocytes appearing to play a more critical role.
\end{abstract}

Sarcocystis neurona is the predominant cause of equine protozoal myeloencephalitis, and it is the most common cause of equine neurologic disease in the United States. Horses are infected by ingesting $S$. neurona sporocysts in contaminated feedstuffs or water. Despite a high rate of exposure based on seroprevalence, the majority of horses do not develop any apparent clinical disease. Serological status and exposure rates appear to be regionally dependent, with approximately $50 \%$ of the horses in the United States being seropositive (MacKay, 1997). The southeast has one of the highest levels of exposure, with seroprevalence ranging between 70 and $80 \%$. Clinical neurologic disease affects approximately $1 \%$ of all horses, suggesting that most horses develop a protective immune response (Dubey et al., 2001). Horses that are mildly immunocompromised because of stress from training, showing, and pregnancy may be more susceptible to disease (Saville et al., 2000). Symptoms vary from acute onset of severe neurologic disease with recumbency within $24-48 \mathrm{hr}$ to vague lameness with muscle atrophy of several months duration. Clinical signs vary based on localization of lesions in the brain and spinal cord as well as other unknown factors. Some horses with severe signs have minimal or unidentifiable lesions, whereas other horses have marked lesions. The pathophysiology and immunology of the disease, as well as the protective immune response, are not well understood and progress has been slowed because of the lack of a good research model.

Because early attempts of using an equine model were unsuccessful (Fenger, 1998; Cutler et al., 2001; Saville et al., 2000), mouse models were established to determine the histological changes associated with infection, the biology of the host-parasite interaction, and the effects of treatment on disease

Received 10 December 2002; revised 9 April 2003; accepted 30 April 2003.

* Center for Molecular Medicine and Infectious Disease, Department of Biomedical Sciences and Pathobiology, Virginia Polytechnic Institute and State University, 1410 Prices Fork Road, Blacksburg, Virginia 24061-0442.

$\dagger$ Edward Via Virginia College of Osteopathic Medicine and Center for Molecular Medicine and Infectious Disease, Department of Biomedical Sciences and Pathobiology, Virginia Tech, Blacksburg, Virginia 24061-0442.

$\ddagger$ Department of Biomedical Sciences and Pathobiology, Virginia Polytechnic Institute and State University, Duck Pond Drive, Blacksburg, Virginia 24061-0442.
(Marsh et al., 1997; Dubey and Lindsay, 1998; Cheadle et al., 2001). Only immunodeficient mouse models develop neurologic disease (Marsh et al., 1997; Dubey and Lindsay, 1998); therefore, they are potentially poor models for determining the mechanisms involved in protective immune response to $S$. neurona infection.

Because immunocompetent mice and $99 \%$ of horses that are exposed do not develop the disease, this suggests that the normal-functioning immune system develops a protective immune response to $S$. neurona infection. This study was undertaken to examine the immune responses of C57BL/6 mice to experimental infection with $S$. neurona. Mice were infected with $S$. neurona merozoites subcutaneously. Immune response was measured by seroconversion and changes in immune cell subsets, as measured by flow cytometry.

\section{MATERIALS AND METHODS}

\section{Maintenance of Sarcocystis neurona cultures}

Sarcocystis neurona merozoites (SnOp-15) were grown and maintained in African green monkey (Cercopithecus aethiops) kidney cells (CV-1 cells, ATCC CCL-70, American Type Culture Collection, Manassas, Virginia) as previously described (Rosypal et al., 2002).

For mouse infections, merozoites were harvested from infected cell cultures by removing the medium and replacing it with Hanks balanced salt solution (HBSS) without calcium and magnesium. Host cells were then removed from the plastic growth surface by use of a cell scraper. This cell mixture was passed through a 27-gauge needle attached to a 10-ml syringe to disrupt the host cells. The suspension was passed through a sterile $3-\mu \mathrm{m}$ filter to remove cellular debris. The merozoite suspension was centrifuged ( $400 \mathrm{~g}$ for $15 \mathrm{~min}$ ) to concentrate the merozoites. The merozoites were resuspended in HBSS, and the number of merozoites in the filtrate was determined using a hemacytometer (Lindsay and Dubey, 2001).

\section{Infection and examination of mice}

Female C57BL/6 mice (4-6 wk old) were obtained from Jackson Laboratories (Bar Harbor, Maine). Mice were infected with $1 \times 10^{7} S$. neurona merozoites subcutaneously. Uninfected age-matched mice served as controls. Blood was collected via the orbital sinus before death. Mice were killed at 14 and 28 days postinfection (PI) with halothane. For the experiments described in this study, data on 15 uninfected controls (day 0) and 10 infected mice at each time point were collected. All uninfected controls are referred to as the "day 0 group" for the duration of this study.

Mice were weighed and necropsied immediately after death. Heparinized blood samples were collected via the retroorbital plexus. Spleens were weighed, and spleen-body weight ratios were determined. Portions 


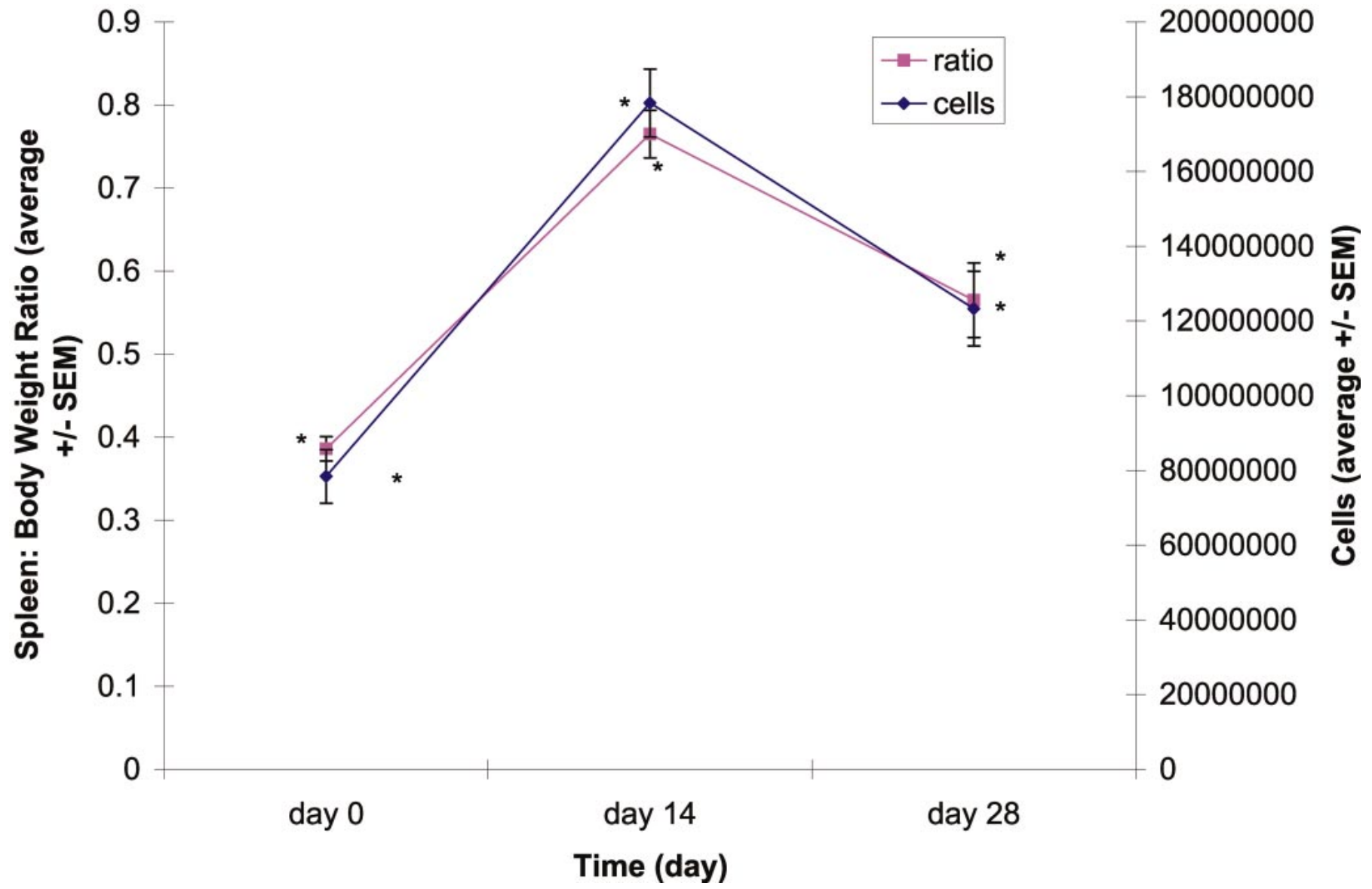

Figure 1. Changes in splenic weight and cellularity associated with infection ( ${ }^{*} P<0.05$; Tukey's test).

of the thymus, spleen, lymph nodes (mesenteric lymph node [MLN], axillary lymph node [ALN], and inguinal lymph node [ILN]), kidney, liver, lung, and brain were taken for histological examination. Sections were fixed in formalin and embedded in paraffin. A board-certified pathologist reviewed all sections. Bilateral sections of spleen and lymph nodes were individually collected and placed in incomplete media.

\section{Blood processing and serology}

Heparinized blood from each mouse was diluted a minimum of 1:4 in incomplete media, Roswell Park Memorial Institute 1640 medium (Thomas Scientific, Swedesboro, New Jersey) without fetal calf serum or L-glutamine, and then layered in a maximum of 3:1 on One-Step (Accurate Chemical, Westbury, New York). Samples were spun at 700 $g$ for $25 \mathrm{~min}$ at room temperature. The buffy coat was collected, and samples were washed 3 times in incomplete media. Samples were then resuspended and used for flow cytometry (Tripp et al., 1997).

Serum samples were collected from each mouse. Serum from each mouse was run individually for the $S$. neurona agglutination assay (Lindsay and Dubey, 2001). Additionally, sera from uninfected $(\mathrm{n}=8)$ and infected $(n=6)$ mice were pooled in groups of 2 serum samples per group and submitted to Research Animal Diagnostic and Investigative Laboratory (RADIL), Columbia, Missouri, for Sendai, Mycoplasma sp., and murine hepatitis virus examinations.

\section{Preparation of splenocytes and lymphocytes}

Spleen and lymph node samples were dissociated with a 3-ml plunger across a metal tissue sieve (Sigma Chemical Co., St. Louis, Missouri). Spleen samples were resuspended in $10 \mathrm{ml}$ of incomplete media. Cells were enumerated using the Casy-1 Model TTC Cell Counter and Analyzer System (Sharfe System, GMbH, Reutingen, Germany). Lymphocytes were centrifuged at $250 \mathrm{~g}$ for $5 \mathrm{~min}$ and resuspended in a minimum volume for flow cytometry. (Gogal et al., 2000)

\section{Flow cytometry}

For each sample, $5 \times 10^{5}$ cells were placed in a 96-well round-bottom plate. Samples were washed with phosphate-buffered saline (PBS) (250 $g$ for $5 \mathrm{~min}$ ). Samples were stained with either PE-B220/FITC-CD69 or FITC-CD62/PE-CD44/Tri-color CD8/Texas Red CD4 at a concentration of approximately $0.5-\mu \mathrm{g}$ stain $/ 10^{6}$ cells in $50-\mu 1$ volume. All antibodies were from Pharmingen (San Diego, California), except Tri-color CD8 and Texas Red-CD4, which were from Cal-Tag (Burlingame, California). Samples were stained for $20 \mathrm{~min}$ at $4 \mathrm{C}$ and then washed with PBS (250 $\mathrm{g}$ for $5 \mathrm{~min}$ ) (Thomas Scientific). Cells were resuspended in PBS and run on the EPICS-XL flow cytometer (Coulter, Hileah, Florida). Ten thousand events were collected per sample (Tripp et al., 1997).

\section{Statistical analysis}

Analysis of variance was conducted using the GLM procedure of the SAS System (version 8.2, SAS Institute Inc., Cary, North Carolina) to test for treatment effects. Standardized residual plots were used to assess model adequacy. Mean separation was performed using Tukey HSD.

\section{RESULTS}

\section{Serology}

All infected animals were seropositive for antibodies to $S$. neurona by day 14 at a minimum of 1:50 dilution of serum. All control animals were seronegative. Serologic analysis for Mycoplasma sp., Sendai, and mouse hepatitis virus was negative for all infected and control mice. 

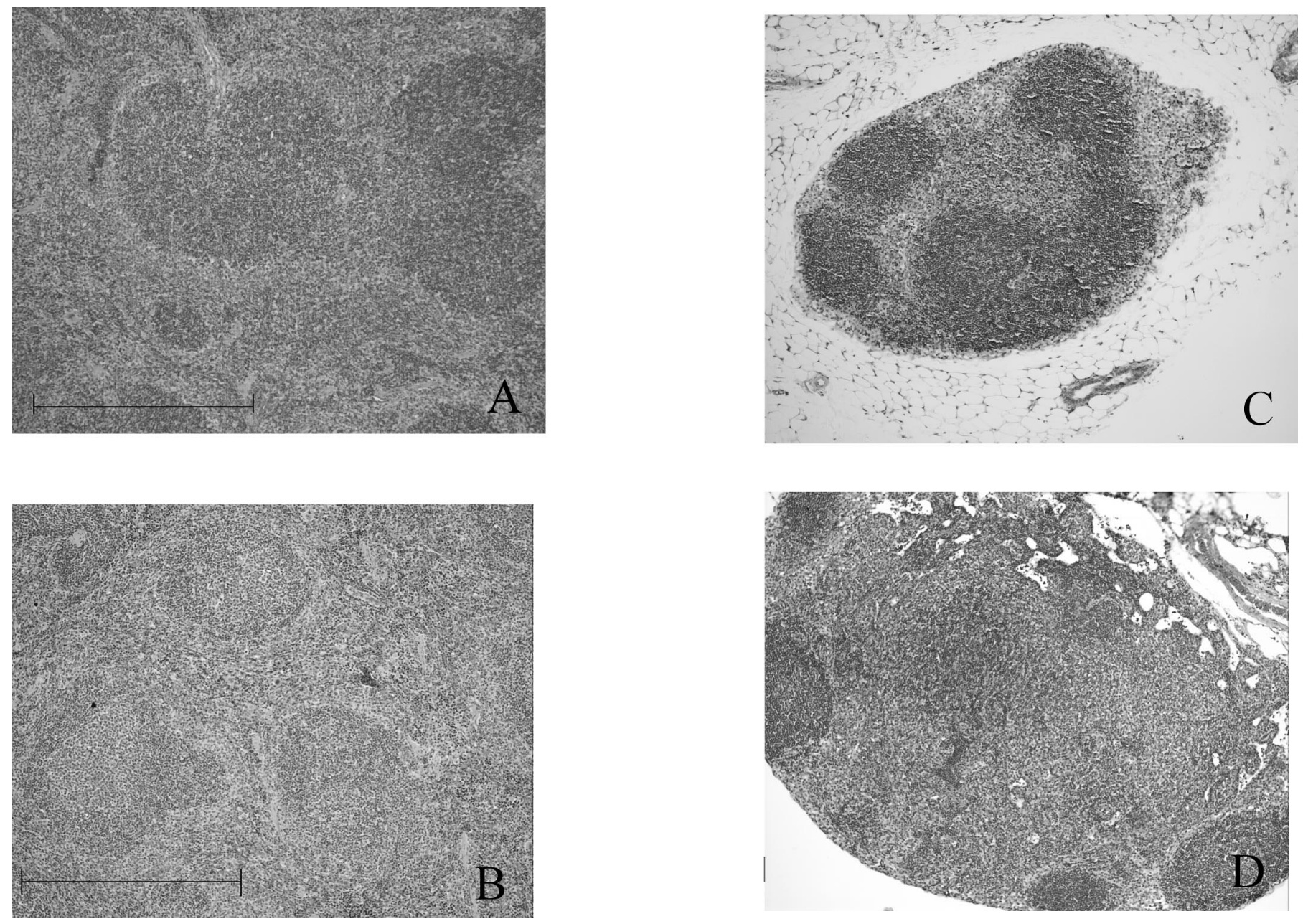

FIGURE 2. Histopathological changes associated with Sarcocystis neurona infection of immunocompetent C57BL/6 mice. A. Spleen from uninfected control $(\mathrm{Bar}=55 \mu \mathrm{m})$. B. Spleen from infected mouse at day 14 PI $(B a r=55 \mu \mathrm{m})$. Multiple germinal centers with lympholysis are present. C. Lymph node from uninfected control $(B a r=18 \mu \mathrm{m})$. D. Lymph node with multiple follicles and germinal centers from infected mouse at day $14 \mathrm{PI}(\mathrm{bar}=10 \mu \mathrm{m})$.

\section{Gross examination of organs and cellularity data}

By day 14 PI, infected animals developed splenomegaly, as determined by a significant increase in cellularity, splenic weight, and an increase in spleen-body weight ratio. (Fig. 1) $(P<0.05)$. However, by day $28 \mathrm{PI}$, the splenomegaly and increased cellularity were in decline, but parameters were still greater than in the uninfected controls $(P<0.05)$. Mice also developed bilateral symmetrical lymphadenopathy involving ILN and ALN as well as enlarged MLN by day 14 PI. All lymph nodes were reduced in size by day 28 PI, but they were still larger than those of the uninfected littermate controls.

\section{Histopathologic analysis}

Histologically, spleens from infected mice at day 14 PI had marked increases in primary and secondary follicles compared with the uninfected controls. Extramedullary hematopoiesis $(\mathrm{EMH})$ was increased, but germinal center numbers and activity were more significant than the EMH. By day 28 PI, the size and numbers of germinal centers were diminishing, but ger- minal center activity remained markedly greater than that of uninfected controls. (Fig. 2A, B)

Lymph nodes became hypercellular, grossly and histologically, by day 14 PI and diminished by day 28 PI (Fig. 2C, D). There were increased numbers of secondary follicles with prominent germinal centers. High endothelial venules, an indicator of cellular recruitment to the lymph nodes, were prominent. By day 28 PI, hypercellularity was diminishing.

Mice at day 14 PI developed a few small sinusoidal foci of mixed inflammatory cells in the liver, predominantly neutrophils and lymphocytes, compared with uninfected controls. The number and size of foci decreased, and in some cases, foci were absent by day 28 PI. There were a few similar perivascular infiltrates present at day 14 PI, which decreased in number and severity by day 28 PI.

No other consistent findings were present in any of the other sections viewed.

\section{Flow cytometry}

The objectives of the flow cytometry experiment were (1) to identify changes in activation (CD44/CD69) or memory 


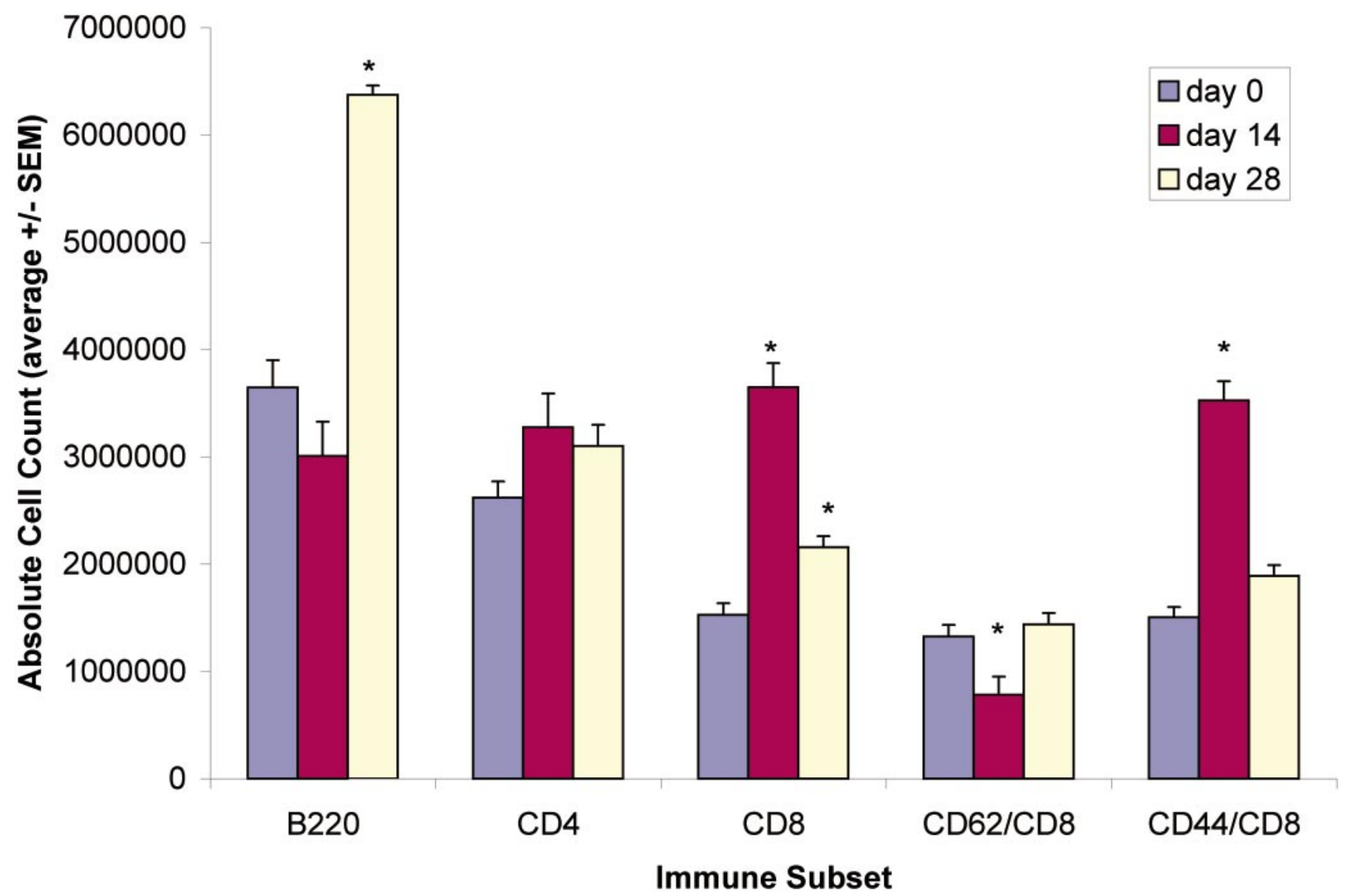

FIGURE 3. Total splenocyte counts of immune subsets $(* P<0.05$; Tukey's test).

(CD44) status (or both) of critical immune subsets (CD4, CD8, B-cell B220) and (2) to determine whether a protective immune response developed. For these reasons, the following antibodies were chosen: CD69, CD62, CD69, B220, CD4, and CD8. CD69 is an early-activation marker that has been frequently used in combination with other cell surface markers to determination activation or down-regulation of a particular population, i.e., B220 or CD8 (Marshall et al., 2001). CD62 and CD44 were chosen because this combination has frequently been used to follow changes in an immune population from early activation to the development of a memory population over time (Topham et al., 1996; Topham and Doherty, 1998; Turner et al., 2001). CD62 is a naive marker that is shed very rapidly after activation. CD44 is a memory cell marker, which can be used to identify the development of a memory population. CD62 and CD44 were chosen because this combination had frequently been used to follow changes in an immune population from early activation to the development of a memory population over time (Mobely and Dailey, 1992; Topham et al., 1996; Topham and Doherty, 1998; Turner et al., 2001).

By day 14 PI, the percentage of B-cells present in the spleen decreased significantly compared with the uninfected controls, but the total number of B-cells decreased only mildly compared with the controls because of hypercellularity (Figs. 3, 4) $(P<$ $0.05)$. There was a marked decrease in the percentage of $\mathrm{B}$ cells in the blood at day 14 PI $(P<0.05)$; the percentage of
B-cells was increasing by day 28 PI. Total B-cell numbers and percentages increased significantly in the lymph nodes and spleen by day 28 PI (Fig. 4) $(P<0.05)$.

There was a marked decrease in the percentage of CD4 lymphocytes in the blood and spleen at day 14 PI (Fig. 5A) $(P<$ $0.05)$. However, the total number of CD4 splenocytes was insignificantly increased at day 14 PI (Fig. 3). Average numbers decreased in the lymph node by day 14 PI but did not reach significance until day 28 PI $(P<0.05)$. Depletion of CD4 cells affected the percentage of both double-positive CD62/CD4 early-activation cells (Fig. 5B) and double-positive memory CD44/ CD4 lymphocytes (Fig. 5C) $(P<0.05)$. The percentage of CD62/CD4 cells rebounded by day 28 PI and CD62/CD4 expression in the spleen were comparable to those of uninfected mice. The expression of CD62/CD4 was still significantly decreased in the blood at day 28 PI $(P<0.05)$. In contrast, percentages of memory cell populations of CD44/CD4 decreased in the spleen, blood, and ALN, and percentages did not rebound by day $28 \mathrm{PI}$.

In contrast to the changes in the CD4 population, there was a significant increase in both total CD8 splenocytes (Fig. 3) and the percentage of CD8-positive lymphocytes in the blood and spleen at day $14 \mathrm{PI}$ (Fig. 6A) $(P<0.05)$. There was an acute and marked decrease in total number of CD62/CD8 splenocytes and the percentage of CD62/CD8 "naive cells" in the blood and spleen at day 14 PI $(P<0.05)$. In contrast, the percentage 


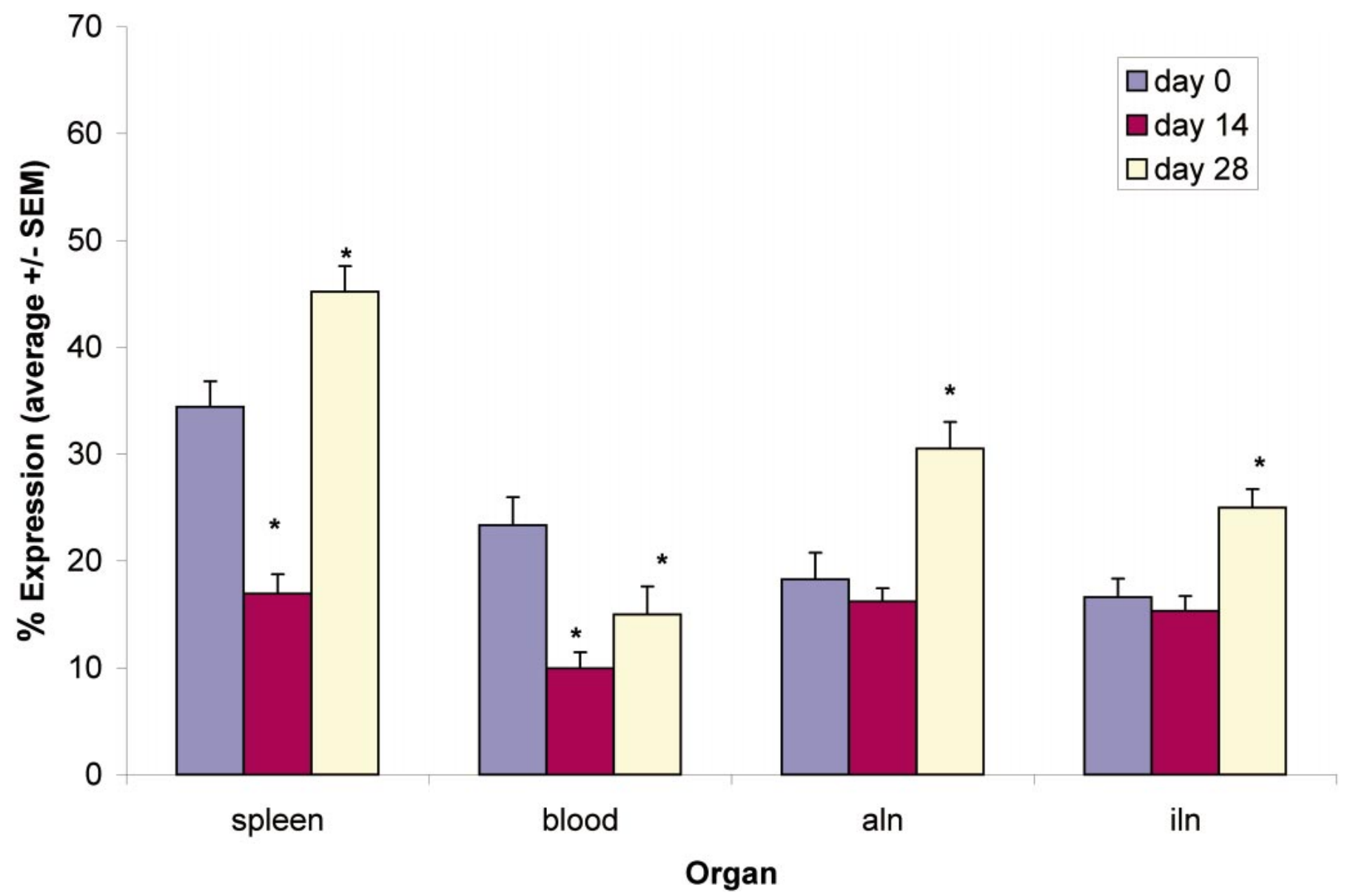

FiguRE 4. Average percent expression of B220 in lymphoid organs $(* P<0.05$; Tukey's test).

of CD62/CD8 showed an increasing trend at day 14 PI in the ILN, which was not significant (Fig. 6B). There was a significant loss of CD62/CD8 cells due to down-regulation of CD62/ CD8 phenotype to CD8 phenotype $(P<0.05)$ (Fig. 6C). By day $28 \mathrm{PI}$, percentages of CD62/CD8 increased in the spleen and ALN. In comparison, there was a significant increase in the percentage of cells that are CD44/CD8 by day 14 PI in the spleen, ILN, and, most significantly, blood (Fig. 6D) $(P<$ $0.05)$. Total numbers of CD44/CD 8 in the spleen increased significantly as well (Fig. 3), and the percentage of CD8 cells that were CD44 increased significantly (data not shown) $(P<0.05)$. By day 28 PI, the percentage of cells that were CD44/CD8 was down-regulated and had returned to levels similar to the levels found in uninfected mice in the spleen. Percentages of CD8 cells in all lymphoid organs examined had decreased by day 28 PI.

\section{DISCUSSION}

The findings described in this study outline the protective immune response of immunocompetent mouse strain (C57BL/ 6) infected with $S$. neurona. Because a reliable equine model is still being developed, murine models, using both immunocompetent and immunodeficient mice, serve as excellent avenues for elucidating immune responses to $S$. neurona infection. From the data presented here, we report that immunocompetent
C57BL/6 mice infected with $S$. neurona develop a transient splenomegaly and bilateral lymphadenopathy that appears to resolve by day 28 PI. Longevity studies from mice killed at greater than 6 mo show very little histopathologic changes consistent with infection (data not shown). The gross splenomegaly was confirmed by spleen-body weight ratios, and the cellularity was confirmed by total cell counts at days 14 and 28 PI. Histologically, the predominant response involved the increased number of follicles and germinal centers, with increased lympholysis, in both the spleens and lymph nodes. The EMH was also mildly increased in the spleens of infected mice.

Flow cytometric data revealed a significant increase in Bcells, based on the percentage of cells within the spleen and lymph nodes as well as total cell splenic numbers. The significant decrease in B-cell percentages in the blood at day 14 PI was likely due to the recruitment of B-cells to other lymphoid organs, as well as the significant increase in CD8 lymphocytes in the blood. The acute significant decrease in the percentage of CD4 cells suggested the acute loss or destruction of cells. The overall decrease in CD4 percentages may also be partially due to the significant increases in B-cell percentages at day 28 PI and the significant increases in CD8 percentages at days 14 and 28 PI. Decreases in CD4 cells appeared to significantly affect both $\mathrm{CD} 62^{+} / \mathrm{CD} 4^{+}$cells and $\mathrm{CD} 44^{+} / \mathrm{CD} 4^{+}$lymphocytes. If the CD4 population was the "most protective" immune cell 


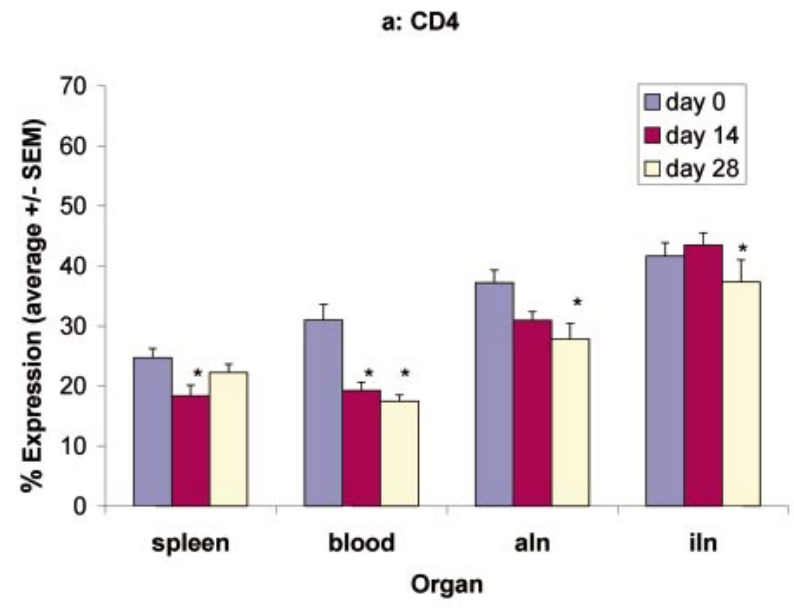

b: $\mathrm{CD} 62 / \mathrm{CD} 4$

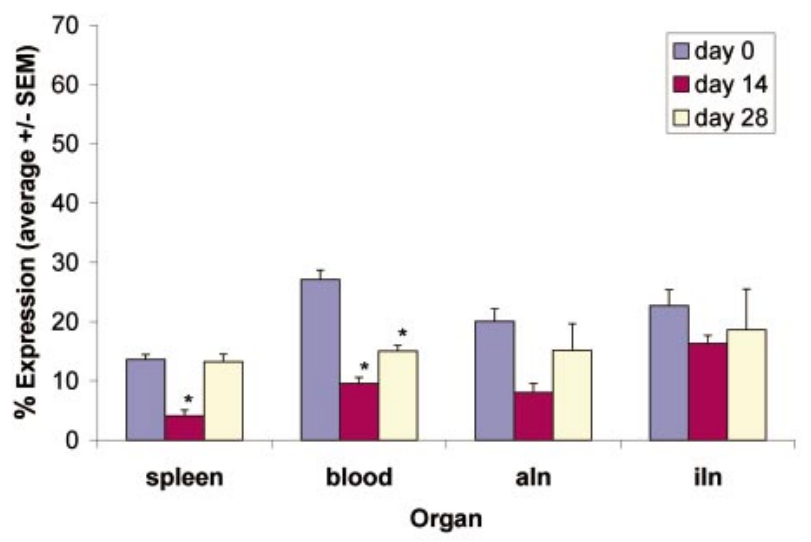

c: $\mathrm{CD} 44 / \mathrm{CD} 4$

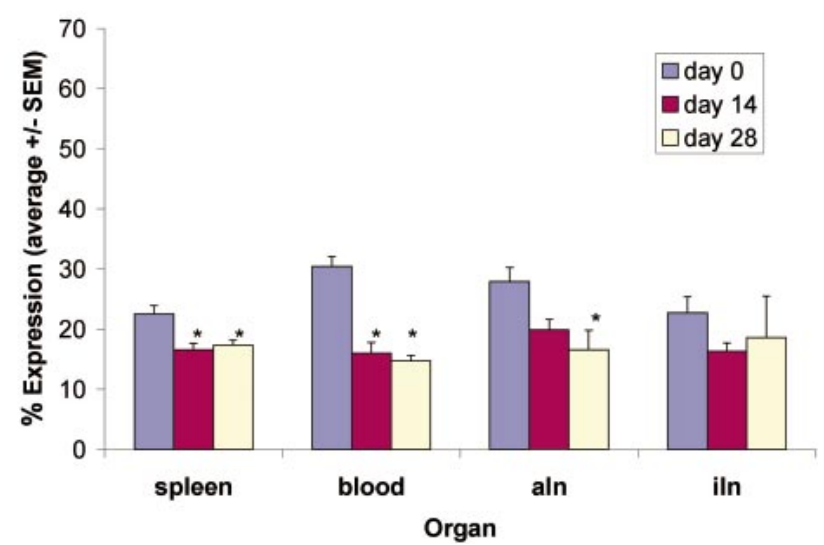

FIGURE 5. Average percent expression of CD4 in lymphoid organs. ALN $=$ axillary lymph node; ILN $=$ inguinal lymph node. A. Expression of CD4. B. Expression of CD62/CD4. C. Expression of CD44/ CD4 $(* P<0.05$; Tukey's test). subset, one would expect to see significant increases in CD4 subsets, rather than decreases.

In comparison, there was a significant increase in the total number of CD8 splenocytes and the percentage of CD8 lymphocytes in the blood and spleen by day 14 PI. Significant increases in CD8 response were predominantly due to down-regulation of $\mathrm{CD}^{2} 2^{+} / \mathrm{CD}^{+}$as evidenced by both significantly decreased total numbers and percentages of $\mathrm{CD} 62^{+} / \mathrm{CD} 8^{+}$, as well as the significantly decreased percentage of CD8 cells that were $\mathrm{CD}^{2} 2^{+}$. This down-regulation of $\mathrm{CD}^{2} 2^{+} / \mathrm{CD}^{+}$was combined with the up-regulation of memory CD44+ ${ }^{+}$subset of CD8 lymphocytes, as indicated by the increase in total numbers of $\mathrm{CD}_{4} 4^{+} / \mathrm{CD}^{+}$splenocytes, increased percentages of $\mathrm{CD}^{+} 4^{+} /$ $\mathrm{CD}^{+}$lymphocytes, and the increase in the percentage of CD8 lymphocytes that were CD44 positive. This marked increase in CD8 population, along with the down-regulation of naive $\mathrm{CD}^{2} 2^{+} / \mathrm{CD}^{+}{ }^{+}$subset, supports the role of this subset in the protective immune response to $S$. neurona infection. By day $28 \mathrm{PI}$, the infection appeared to be resolving based on histopathology and immune cell subsets.

In 2 sets of data points in the ILN and ALN, there was wide variation in the CD62 and CD44 subsets at day 28 PI. Data were compiled from 2 different experiments, with 1 set revealing very low numbers of CD62 and CD44, of CD4 and CD8 subsets, and the other producing very high percentages of CD44 and CD62 subsets. These differences were not seen in other organs, i.e., blood and spleen. All data were analyzed with the same program and cytosettings on the flow cytometer. We suggest that this variance may be due to subtle changes in the infection, pathogenicity of the $S$. neurona strain, and passage number or preparation of inocula. In most cases, interferon (IFN)-gamma knock-outs were infected concurrently. They all died between days 28 and 32 PI, and this was the main quality control. Additional experiments will be conducted to address this variance.

Based on the data presented in this study, we propose that the protective immune response in immunocompetent mice is due to a combined increased humoral and cell-mediated immune responses. All infected mice seroconverted by day 14 PI, and there was a marked increase in total B-cell numbers and percentages of B-cells within lymphoid-specific organs. The changes in B-cell populations combined with germinal center development in lymphoid organs suggest a supportive role of the humoral response with respect to a protective immune response. However, it is likely that the cell-mediated immune response to $S$. neurona is more important, as based on previous data (Dubey and Lindsay, 1998; Rosypal et al., 2002) that support the role of IFN-gamma in directing the protective immune response. Further, our data suggest that during the early stages of immune response, a significant non-subset specific loss of CD4 cells occurs, whereas there is a significant specific upregulation of memory CD8 response. We believe that, as with Toxoplasma gondii, it is the IFN-gamma production by both the CD4 and CD8 cells that most likely provides the most critical component of the protective immune response in the C57BL/6 immunocompetent host. With T. gondii, there is a synergistic effect of CD4 and CD8 cells, but deletion studies have demonstrated that CD8 cells played a more crucial role. In T. gondii infection, CD4 cells function to produce IFN-gamma, stimulate natural killer cells, which also produce IFN-gam- 


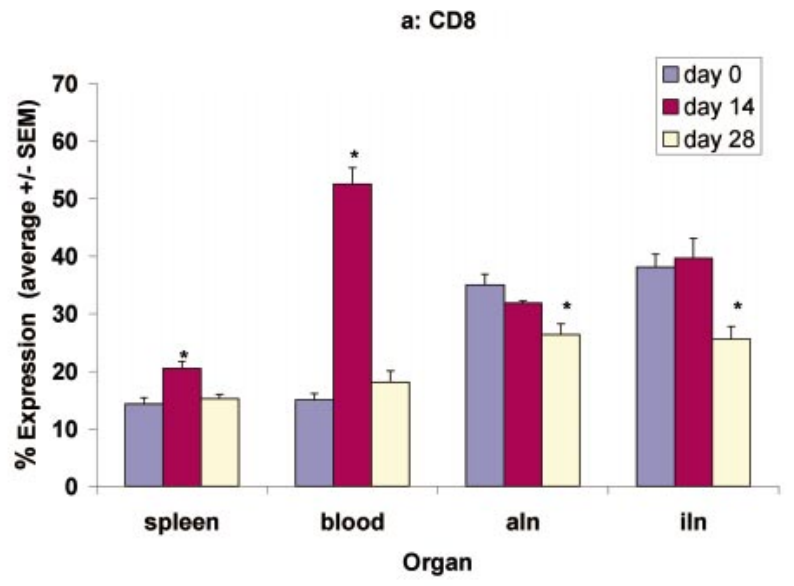

c: Percent CD8 that are CD62

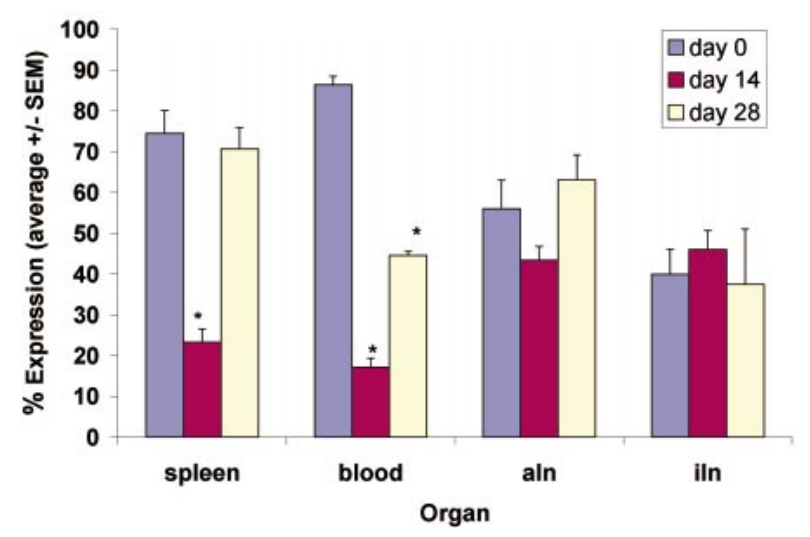

b: CD62/CD8

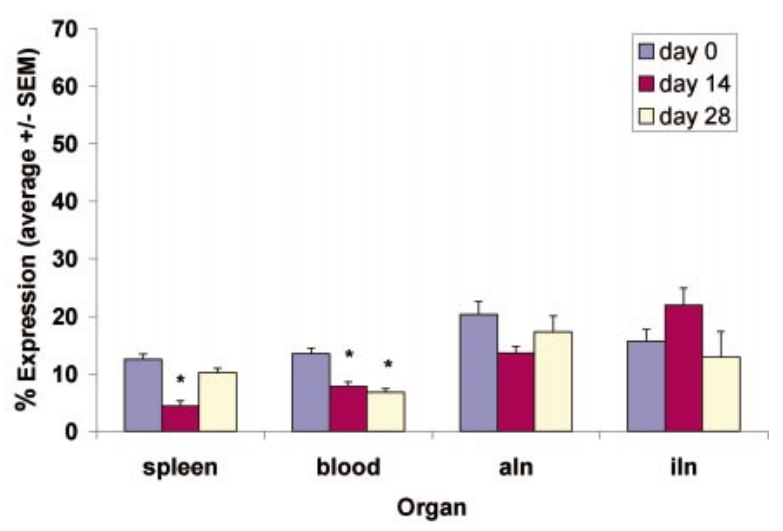

d: CD44/CD8

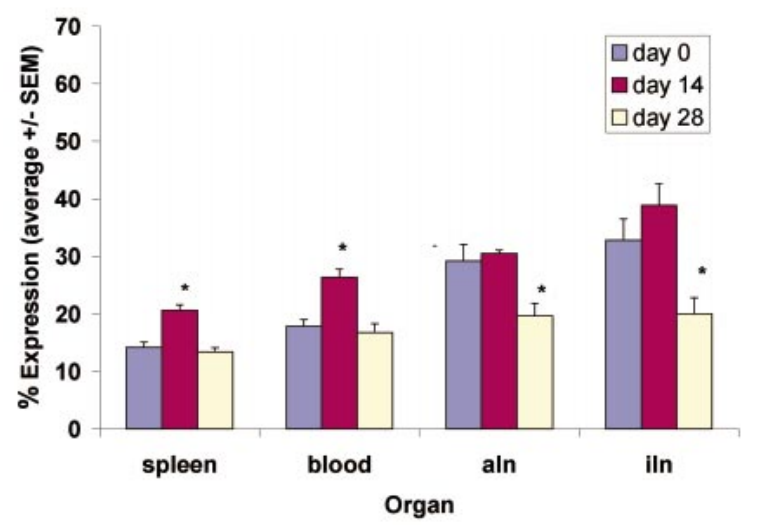

FIgURE 6. Average percent expression of CD8 in lymphoid organs. ALN = axillary lymph node; ILN = inguinal lymph node. A. Expression

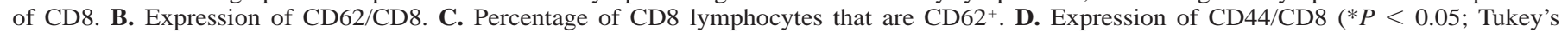
test).

ma, stimulate the development of a Th1 response, and stimulate IFN-gamma-dependent reactive nitrogen intermediate (RNI) killing of parasites (Denkers and Gazzinelli, 1998). There is a considerable overlap between CD4 and CD8 function. CD8 responsibilities include, but are not limited to, IFN-gamma production, CTL activity including killing infected cells, and IFNgamma-dependent RNI killing of parasites (Denkers and Gazzinelli, 1998). IFN-gamma was the predominant cytokine associated with CD8-mediated protection from $T$. gondii, but it is also possible that other CD8-mediated immune modulators, i.e., chemokines and cytokines (Gazzinelli et al., 1993; Hooper et al., 1997; Hayashi et al., 1998; Cua et al., 2001), are also essential. It is possible, that IFN-gamma as well as other immunomodulators may be involved in the protective immune response to $S$. neurona as well. At this time, based on the data presented in this study, it appears that CD8 cells may be the most critical element in the cell-mediated immune response to S. neurona.

\section{ACKNOWLEDGMENTS}

This study was supported by a CSREES Animal Health and Disease grant to S.G.W., D.S.L., and R.M.G. We appreciate the help of Dan Ward in the statistical analysis.

\section{LITERATURE CITED}

Cheadle, M. A., S. Tanhauser, T. Scase, J. Dame, R. Mackay, P. GinN, AND E. C. GREINER. 2001. Viability of Sarcocystis neurona sarcocysts and dose titration in gamma-interferon knock-out mice. Veterinary Parasitology 95: 223-231.

Cua, D., B. Hutchins, D. LaFace, S. Stohlman, and R. Coffman. 2001. Central nervous system expression of IL-10 inhibits autoimmune encephalitis. Journal of Immunology 166: 602-608.

Denkers, E. Y., AND R. T. GAZZINELli. 1998. Regulation and function of T-cell mediated immunity during Toxoplasma gondii infection. Clinical Microbiology Review 11: 569-588.

Dubey, J. P., AND D. S. LindSAY. 1998. Isolation in immunodeficient mice of Sarcocystis neurona from opossum (Didelphis virginiana) faeces and its differentiation from Sarcocystis falcatula. International Journal for Parasitology 28: 1823-1828.

, W. Saville, S. Reed, D. Granstrom, And C. A. SPeER. 2001. A review of Sarcocystis neurona and equine protozoal myeloencephalitis. Veterinary Parasitology 95: 89-132.

Fenger, C. 1998. Treatment of equine protozoal myeloencephalitis. Compendium on Continuing Education for the Practicing Veterinarian 20: 1154-1157.

Gazzinelli, R., I. Eltoum, T. Wynn, And A. Sher. 1993. Acute cerebral toxoplasmosis is induced by in vivo neutralization of TNF-alpha and correlates with the down-regulated expression of inducible nitric oxide synthase and other markers of macrophage activation. Journal of Immunology 151: 3672-3681.

, Y. Xu, S. Hieny, A. Cheever, And A. Sher. 1992. Simulta- 
neous depletion of $\mathrm{CD} 4+$ and $\mathrm{CD} 8+\mathrm{T}$ lymphocytes is required to reactivate chronic infection with Toxoplasma gondii. Journal of Immunology 149: 175-180.

Gogal, R., M. Prater, M. Johnson, and S. Holladay. 2000. Bilateral sections of spleen and thymus in rodents exhibit homogeneity in leukocyte marker expression. Toxicology 157: 217-223.

Hayashi, S., C. Chan, R. Gazzinelli, and F. Roberge. 1998. Contribution of nitric oxide to the host parasite equilibrium in toxoplasmosis. Journal of Immunology 156: 1476-1481.

Hooper, D., O. Bagasra, J. Marini, A. Zhorek, S. Ohnishi, R. Kean, J. Champion, A. Sarker, L. Bobriski, J. Farber, T. Akaike, H. MAEDA, AND H. KopRowsKI. 1997. Prevention of experimental allergic encephalomyelitis by targeting nitric oxide and peroxynitrite: Implications for treatment of multiple sclerosis. Proceedings of the National Academy of Sciences of the United States of America 94: $2528-2533$.

LindSAY, D. S., AND J. P. DubEy. 2001. Direct agglutination test for the detection of antibodies to Sarcocystis neurona in experimentally infected animals. Veterinary Parasitology 95: 179-186.

MACKAY, R. 1997. Equine protozoal myeloencephalitis. Veterinary Clinics of North America: Equine Practice 13: 79-96.

Marsh, A., B. Barr, J. Lakritz, R. Norhausen, J. Madigan, and P. ConRAD. 1997. Experimental infection of nude mice as a model for Sarcocystis neurona-associated encephalitis. Parasitology Research 83: 706-711.

Marshall, D., S. Turner, G. Belz, S. Wingo, S. Andreansky, M. Sangster, J. Riberdy, T. Liu, and P. Doherty. 2001. Measuring diaspora for virus specific $\mathrm{CD} 8+\mathrm{T}$ cells. Proceedings of the Na- tional Academy of Sciences of the United States of America 98: $6313-6318$

Mobely, J., AND M. Dailey. 1992. Regulation of adhesion molecule expression by CD8 $\mathrm{T}$ cells in vivo. Differential regulation of gp90mel14 (LE-CAM-1), Pgp-1, LFA-1 and VLA-4 alpha during the differentiation of cytotoxic $\mathrm{T}$ lymphocytes induced by allografts. Journal of Immunology 148: 2348-2356.

Rosypal, A. C., D. S. Lindsay, R. B. Duncan, S. A. Ahmed, A. M. ZAJAC, AND J. P. DUBEY. 2002. Mice lacking the gene for inducible or endothelial nitric oxide are resistant to sporocyst induced Sarcocystis neurona infections. Veterinary Parasitology 103: 315-321.

Saville, W., S. Reed, P. Morely, D. Granstrom, C. Kohn, K. HinchCLIFF, AND T. WITTUM. 2000. Analysis of risk factors for the development of equine protozoal myeloencephalitis in horses. Journal of the American Veterinary Medical Association 217: 1174-1180.

TOPHAM, D., AND P. DOHERTY. 1998. Longitudinal analysis of the acute Sendai virus-specific CD4+ T cell response and memory. Journal of Immunology 161: 4530-4535.

R. Tripp, A. Hamilton-Easton, S. SARwar, and P. Doherty. 1996. Quantitative analysis of the influenza virus-specific CD4+ T cell memory in the absence of B cells and Ig. Journal of Immunology 157: 2947-2952.

Tripp, R., A. Hamilton-Easton, P. Cardin, P. Nguyen, F. Behm, S. Woodland, P. Doherty, AND M. Blackman. 1997. Pathogenesis of an infectious mononucleosis-like disease induced by a murine gamma-herpes virus: Role for a viral superantigen? Journal of Experimental Medicine 185: 1641-1650.

Turner, S., R. Cross, W. Xie, And P. Doherty. 2001. Concurrent naïve and memory CD8+ T cell responses to an influenza A virus. Journal of Immunology 167: 2753-2758. 